\title{
Foreign Language Learning via Mobile Devices during a Language Immersion Program
}

\author{
Eleni Mavropoulou \\ Aristotle University of Thessaloniki \\ Panagiotis Arvanitis
}

Aristotle University of Thessaloniki

\begin{abstract}
The progress of technology and the complete integration of its products in our daily lives is now a reality. In addition to this, more and more young children now own their personal mobile devices, most of which have a connection to the internet. These new portable devices offer unlimited possibilities to their users, yet they also create more and more challenges in the field of learning. Inevitably, Mobile-assisted language learning (MALL) as a subcategory of Mlearning is also affected. The purpose of this paper is to present students' perceptions on the use of an application in the process of learning French as a foreign language. To this end, we developed an application for mobile devices in real teaching conditions, which respects the principles of the Common European Framework of Reference for Languages (CEFR). Experimental quantitative research was carried out in order to explore the students' experience concerning the application as a portable learning tool, completely integrated into the course. The target group we addressed was international students from various countries in Europe, Asia and America, who were taught French during a language immersion program, as part of a language stay in Saint Raphaël in France.
\end{abstract}

Keywords: mobile-assisted language learning, foreign language, application, language immersion program

\section{Introduction}

In a period that distances are being eliminated and cooperation between countries in trade, economy, tourism and research are becoming global, the need to learn foreign languages is growing worldwide. Foreign language teaching takes place in schools, in foreign language centers, through private lessons in lifelong and/or distance learning or even through a language immersion program.

A language immersion program is a method developed to teach people a particular foreign language in a natural way, while being in the country of the target language, achieving thus, rapid progress while also having the joy of meeting people and learning about the local culture. "The term immersion refers to the perception of being surrounded by a substance or liquid" (Blyth, 2018, p.1). Its metaphorical sense of being surrounded by language and culture is "typically describing a kind of enhanced language learning" (Blyth, 2018, p. 1). During these 
programs, one can meet students from all over the world, with the same goal in mind; that is to learn the language in the country where it is spoken, through a course that matches their preferences. This approach maximizes the time the student gets to practice the language they are learning, thus achieving better results in areas such as knowledge of a foreign language, knowledge of the native language and understanding characteristics of other cultures.

\section{Literature review}

"As digital technology has become more sophisticated, its tools and applications can be used in and outside the classroom, in both formal and informal settings, in order to increase students' motivation" (Arvanitis, Krystalli \& Panagiotidis, 2018, p. 43). Research demonstrates also that "mobile-assisted language learning helps to create language immersion, which effectively motivates the learners further" (Shi, Luo, \& He 2017, p. 1) and that "mobile devices such as laptops, personal digital assistants, and mobile phones have become a learning tool with great potential in both classrooms and outdoor learning" (Sung, Chang \& Liu, 2016, p. 252). It is obvious fact that mobile application usage can enable a variety of teaching innovations that assist students in pursuing knowledge and language skills (Sung \& al., 2020).

Furthermore, using new technologies in the classroom is now a justified practice as digital technology is part of the everyday life for this decade's learners. In addition to that, there is a need to redefine literacy and incorporate technology into almost every aspect of the lesson (Ahmed \& Nasser, 2015).

The fact that learning a foreign language in the country of the target language has better results for the students isn't because they live in this context. According to Kramsch and Andersen, "the problem with learning a language from live context is that context itself cannot be learned, it can only be experienced, or apprenticed in" (Kramsch \& Andersen, 1999, p. 33) and that the solution is "to make the context learnable by entextualizing it" through the use of multimedia. According to M. (Snow, 1987) immersion is an excellent example of communicative language teaching and there is still a great need to develop appropriate, challenging materials. Also, it is very important to continue searching for effective ways of teaching languages via immersion. Moreover, (Bakhov \& Honcharenko-Zakrevska, 2018, p. 6) “...learning through immersion not only is suitable for most students but also is possibly the only opportunity for some students to learn a foreign language.".

\section{Research methodology}

For the purposes of the research, we used an application we created as a tool for French language learning for mobile devices in real teaching conditions, which respects the principles of the Common European Framework of Reference for Languages. This application was published for Android and iOS app in English and it was used by the foreign students during the language immersion program. After using the application during the French language course, and in order to explore students' perceptions, an experimental, qualitative and quantitative research was carried out.

The target group we addressed consisted of 60 international students aged 11-18, from various countries in Europe, Asia and America, who were taught French during a language immersion program, as part of a language stay in Saint Raphaël in France. The students of the language immersion program were taught six foreign language lessons with the "traditional" learning method - student book and exercise book and six lessons exclusively with the use of 
the application. The purpose was to identify the perceptions of students concerning its overall assessment as a portable learning tool. After completing these 12 lessons, the research was concluded, the data were collected, the quantification followed and finally the analysis.

A questionnaire was distributed in order to conduct our research. The questionnaire consisted of 18 questions, it was anonymous and was accompanied by written instructions on how to complete it. We limited ourselves to very concise and standardized instructions to avoid comprehension difficulties.

An emphasis should be given to the fact that for the completion of the questionnaire by the students, an oral translation was done in English, Italian and Spanish to the degree that was allowed by the use of mobile devices for the translation and comprehension of the questions. There followed the analysis of the data collected from the questionnaire.

\section{Analysis}

The questionnaire, distributed in July 2018, consisted of 18 questions which were structured around five axes. Specifically, these axes examine the data of the participants, their contact with ICT, their position on the learning outcomes of the application, its usability and its technical implementation. The responses were 60 in total and came exclusively from the students during the language immersion program.

The first three questions of the questionnaire concern the gender, the age and the nationality of the students. The next two questions aim to gather information about the students' contact with ICT. Questions 5 and 6 refer to the use of the application in language learning. The next eight questions relate to students' views on the application in relation to language learning, while the last three questions relate to their views on the technical characteristics of the application.

Out of the total number of students, 23 were boys, and 37 were girls: 45 out of 60 were between 14 and 16 years old. The nationalities of the students varied. The majority (of the participants) were Swedes and Swiss. More specifically, from the 60 students, fifteen were Swedes, ten Swiss, seven Austrians, five Spanish, four Finns, four Germans, two Americans, two Turkish, two Norwegians, two Danes, one Russian, one Dutch and one Italian.

When asked how often they use new technologies in their daily lives, 9 out of 60 students said they use them less than two hours per day, while 51 said they use them more than four hours per day.

Regarding the way they choose to communicate in their daily life, 45 out of 60 replied that they communicate via Viber, 29 out of 60 via Skype and 47 out of 60 via Facebook, followed by WhatsApp communication for 29 students, Instagram for 49, communication via E-mail for 39 and SMS for 37. Regarding the use of an application on a mobile device for the scope of learning a foreign language, we can see that the majority has already used an application (56 out of 60). Google Translate is superior, as it is used by 51 students, compared to Duolingo, which comes second in use with 30 students, while Babbel follows with only two students.

When asked about how interesting they found the change (use of the application) in the curriculum and the way the course was conducted, the prevailing answer is "very interesting" (52 students out of 60 ). 
When asked about the usefulness of integrating the application into foreign language learning, it is evident that the majority of the students find it useful (57 students out of 60).

In terms of what skills they think they have improved and assimilated through the use of the application, we have observed almost to a full degree an improvement in written comprehension (60 students out of 60), in oral comprehension (56 out of 60 students) and (95 out of 100 students) followed by an improvement in written production (35 out of 60 students) and in oral production (32 out of 60 students).

All students stated that they progressed more in terms of acquiring more vocabulary, improving pronunciation (55 out of 60 students) and assimilating grammar (56 out of 60 students) and less in improving spelling (56 out of 60 ) and comprehension of syntax (51 out of 60 ).

In terms of teaching, 56 students out of 60 were in favor of the use of mobile devices, while the use of multimedia (video and podcasting) benefited 57 students out of 60 in terms of oral comprehension. For all students, it was easy to point out the mistakes, while also the same number of students found it easy to provide additional clarifications.

Moreover, 38 students out of 60 in total consider the application environment to be very userfriendly, while the rest consider it less user-friendly (22 out of 60 students).

The majority of the students consider the navigation user-friendly (29 students out of 60), 31 students consider it to be less user-friendly.

The last question required students to record the difficulties they encountered during the course. After the answers were collected, they were grouped into specific categories of problems. The problems refer to technical issues of the application.

\section{Discussion}

This study showed the views of the students of a language immersion program in relation to the application used as complimentary educational tool for French learning. Studying the data collected from the questionnaires, the following important conclusions can be drawn: All students have daily involvement with ICT and often use it for communication. Many students have already used a few commercial language learning applications. This previous experience probably predisposes learners positively to use another learning application. The results of the answers concerning the specific application that we provided to them show that the students find the lessons with the application more interesting than the traditional language learning lessons. They also believe that it helped them develop their language skills, especially in understanding and producing written content. Multimedia elements such as video and podcasting also helped them a lot in improving their oral content. The ease of use of the feedback and clarifications was considered satisfactory, but with plenty of room for improvement. Finally, both the application environment and its navigation also need improvement.

\section{Conclusion}

The findings of this study highlighted the significance of using mobile assisted language learning applications as complimentary educational tools and suggest their effectiveness. Additionally, participants believe that mobile devices are useful instructional tools and the integration of technology leads to improved performance and better learning results. 
Prior research has demonstrated that mobile devices as learning tools promote motivation, learner autonomy and creativity and they help students to develop IT skills (Arvanitis, Krystalli \& Panagiotidis, 2016). It is very important that an application for foreign language learning can encourage students to identify the phonetic aspects of a foreign (Sung \& al., 2020).

As we live"...in a digitally globalized world, an increasing number of learners are learning foreign languages outside a formal and structural classroom-based education" (Arvanitis, 2019 , p. 1). The guided learning of a foreign language with an appropriate application and a teacher, in combination with real communication circumstances in the original country of use, would be the ideal way of learning a foreign language. Last, as it is evident that mobile devices gain more and more ground in diverse sectors of life worldwide, future research in this direction is required for better learning outcomes.

\section{References}

[1] Ahmed, K., \& Nasser, O. (2015). Incorporating iPad Technology: Creating More Effective Language Classrooms. TESOL Journal, 6(4), 751-765.

[2] Arvanitis, P. (2019). Self-Paced Language Learning Using Online Platforms. The Handbook of Informal Language Learning, 117-138.

[3] Arvanitis, P., Krystalli, P., \& Panagiotidis, P. (2016). Tablets as instructional tools in the foreign language classroom: the teacher perspective (No. IKEECONF-2016-679). IATED Academy.

[4] Arvanitis, P. \& Krystalli, P. \& Panagiotidis, P. (2018). Technology as A Motivational Factor in Foreign Language Learning.. 1. 43-53.

[5] Bakhov, I., \& Honcharenko-Zakrevska, N. (2018). Implementation of the Concept of Language Immersion In Learning Foreign Languages.

[6] Blyth, C. (2018). Immersive technologies and language learning. Foreign Language Annals, 51(1),

[7] 225-232.

[8] Kramsch, C., \& Andersen, R. W. (1999). Teaching text and context through multimedia. Language Learning \& Technology, 2(2), 31-42.

[9] Shi, Z., Luo, G., \& He, L. (2017). Mobile-assisted language learning using WeChat instant messaging. International Journal of Emerging Technologies in Learning (iJET), 12(02), 16-26.

[10] Snow, M. A. (1987). Immersion Teacher Handbook. Educational Report Series.

[11] Sung, C. M., Ahmad, M., Mansor, N. R., Rashid, R. A., \& Abdullah, N. A. C. (2020, April). The Effectiveness of Mobile Application in Learning Malay Foreign Language. In Journal of Physics: Conference Series (Vol. 1529, No. 4, p. 042064). IOP Publishing.

[12] Sung, Y. T., Chang, K. E., \& Liu, T. C. (2016). The effects of integrating mobile devices with teaching and learning on students' learning performance: A meta-analysis and research synthesis. Computers \& Education, 94, 252-275. 